\title{
A CONTRIBUIÇÃO DA POLÍTICA AGRÍCOLA PARA O DESENVOLVIMENTO DO AGRONEGÓCIO NAS MACRORREGIÕES BRASILEIRAS ${ }^{1}$
}

\author{
Débora Freire Cardoso ${ }^{2}$ \\ Erly Cardoso Teixeira ${ }^{3}$
}

RESUMO:O objetivo deste artigo é determinar os efeitos de longo prazo do subsídio ao crédito rural sobre a produção, o comércio externo e a competitividade (via preços) do setor agropecuário na economia das macrorregiões brasileiras. As simulações foram realizadas com a aplicação do Projeto de Análise de Equilíbrio Geral da Economia Brasileira (Paeg). Verifica-se que a política de crédito rural representa importante estímulo à cadeia do agronegócio brasileiro, tendo em vista os impactos positivos sobre a produção, as exportações da agropecuária, e a expansão das indústrias com forte ligações com o setor agrícola, como químicos e indústria de alimentos e transportes. Ainda, a política está associada a ganho de competitividade (via preços) das commodities agropecuárias nacionais no mercado externo.

Palavras-chave: Crédito rural, subsídios, agropecuária, PAEG, equilíbrio geral.

\begin{abstract}
The objective of this paper is to determine the long-term effects of rural credit on agricultural production, trade and competitiveness (through prices) in the Brazilian regions. The simulations were performed applying the General Equilibrium Analysis Project of the Brazilian Economy (PAEG). The results suggest that the rural credit policy represents an important stimulus to the entire Brazilian agribusiness chains given the positive impacts on agriculture production, exports, and expansion of industries with strong linkages with the agricultural sector. Also, the policy is associated with agricultural competitiveness gains (through prices) in foreign markets.
\end{abstract}

Key words: Rural credit, subsidy, agriculture, PAEG, general equilibrium

1 Os autores agradecem à Fapemig o apoio ao Projeto de Análise de Equilíbrio Geral da Economia Brasileira (PAEG) (Processo: SHA - APQ - 00608-11)

2 Doutoranda em Economia pela Universidade Federal de Minas Gerais (UFMG). Email: dfreirecardoso@gmail. com.

3 Ph.D., Professor Titular da Universidade Federal de Viçosa (UFV). E-mail: teixeira@ufv.br. 


\section{Introdução}

O intervencionismo estatal constitui tema complexo e polêmico e divide a teoria econômica em correntes antagônicas. De um lado, estudiosos defendem que o mercado é eficiente por seus próprios mecanismos e que a intervenção gera ineficiências alocativas e distributivas e custo social. Na extremidade oposta, há os que insistem que a interferência é necessária, uma vez que, segundo esses autores, os mecanismos de ajuste do mercado são falhos.

Entre as políticas intervencionistas, destaca-se o subsídio à produção agropecuária. Esse tipo de política, muito empregada no passado, continua amplamente utilizada, principalmente nos países desenvolvidos, no intuito de promover a produção e garantir renda aos produtores rurais. Contudo, os efeitos causados por políticas setoriais intervencionistas, mesmo sobre o próprio setor que recebe a intervenção, são incertos, uma vez que dependem da estrutura produtiva da economia e das distorções promovidas nos demais setores, dada a interdependência entre as atividades. Nesse sentido, questionam-se os impactos setoriais dos subsídios aplicados à agricultura brasileira por meio da política de equalização das taxas de juros.

A intervenção estatal por meio de subsídios é justificável na presença de externalidades, no caso de bens públicos, no caso de monopólios naturais, quando os mercados são incompletos, quando há assimetria na informação e em situações de desequilíbrio macroeconômico, ou seja, quando ocorrem falhas de mercado (CARVALHO, 2001; MONTALVÃO, 2009).

No caso do Brasil, os produtores enfrentam uma grave falha de mercado relacionada com as taxas de juros prevalecentes na economia. Isto é, a taxa de juros básica da economia (Selic) não é definida no mercado, sua definição é administrada pelo Comitê de Política Monetária (COPOM), órgão do Banco Central (BCB), e visa a atender a objetivos relacionados à contenção das taxas de inflação. Assim, desde a implementação do Plano 
Real, a taxa de juros básica da economia é mantida em níveis bastante elevados. Taxas de juros tão altas representam uma falha de mercado, uma vez que incentivam aplicações financeiras em detrimento de aplicações produtivas. Diante disso, alguns setores necessitam de políticas setoriais que os incentivem, uma vez que seriam inviáveis nas taxas de juros fixadas para toda a economia, e este é o caso da agricultura.

À luz da experiência internacional, os países membros da Organização para a Cooperação e Desenvolvimento Econômico (OCDE) destinam elevado volume de recursos ao setor agrícola, chegando a um grau de proteção, medidos pelo Producer Support Estimate (PSE), da ordem de $30 \%$ da Receita Total da Agricultura. Entre esses países, o Japão chega a um nível de proteção de 58\%, seguido da União Europeia (34\%), Canadá (22\%), México (21\%) e Estados Unidos, com 17\% (OCDE, 2005).

Quando se considera o Brasil, de acordo com a OCDE (2005), sua taxa de proteção à agricultura é relativamente baixa comparada a dos países mais desenvolvidos: situa-se em cerca de 3,0\% da Receita Total da Agricultura. A maior parte da proteção é destinada aos produtores através do crédito subsidiado, sendo o restante destinado a serviços como pesquisa e extensão, treinamento e desenvolvimento de infraestrutura rural (OECD, 2005). Atualmente, o crédito rural é subsidiado via política de Equalização das Taxas de Juros (ETJ), que proporciona ao produtor financiamento a juros mais baixos do que os praticados no mercado.

Formalmente, a ETJ é uma ação destinada à cobertura do diferencial de taxas entre o custo de captação dos recursos pelas instituições financeiras oficiais, acrescido dos custos administrativos e tributários dessas instituições, e os encargos cobrados do tomador final do crédito (MINISTÉRIO DA FAZENDA, 2003). Com a ETJ, o Governo Federal busca ampliar compulsoriamente a participação dos bancos privados no financiamento ao setor rural, como forma de ampliar, sem onerar muito o Tesouro, o volume de recursos disponíveis ao setor (GONÇALVES NETO, 1997). Dessa forma, a partir da intermediação do sistema 
financeiro ${ }^{4}$, o Governo implementa uma política de subsídios ao setor agrícola por meio de um programa de crédito rural com juros abaixo daqueles que vigoram no mercado. Pagando juros mais baixos, o agricultor toma o crédito emprestado e o aplica na produção, gerando efeitos no setor agrícola e nos demais setores da economia.

De acordo com Castro e Teixeira (2004), a política de ETJ garante cerca de $30 \%$ do total de recursos aplicados na agricultura mediante crédito rural, configurando uma importante subvenção à agropecuária brasileira, que tem contribuído, por um lado, para maior demanda por insumos agrícolas, e, por outro, para a expansão da produção no setor. Uma forma de se pensar nos efeitos da política sobre a agropecuária é que o subsídio via crédito rural viabiliza maior produção na medida em que permite aos produtores que enfrentam restrição na compra de insumos aumentarem as compras dos mesmos.

A análise do impacto do crédito na produção agropecuária, entretanto, não constitui tarefa trivial. Segundo Castro e Teixeira (2005), alguns benefícios do crédito, como a formação de capital, podem ter efeitos no longo-prazo, o que dificulta sua mensuração. É preciso considerar também a possibilidade de substituição de recursos próprios pelos recursos oficiais do crédito, chamada de fungibilidade, que conduz a uma redução da eficiência na aplicação dos recursos. Ainda, mesmo quando utilizado no aumento da aquisição de insumos, seu impacto na produção pode não ser sentido devido a condições exógenas como o clima.

Estudos como os de Araújo e Meyer (1979), Simon (1992) e Castro e Teixeira (2012), todavia, estimaram que o crescimento do consumo de insumos agropecuários, como fertilizantes e máquinas, estaria correlacionado com o aumento do volume de crédito no Brasil. Nesse sentido, é possível considerar a hipótese de que o setor agrícola enfrenta

4 O Banco Central impõe exigências sobre os recursos captados pelas agências financeiras a serem direcionadas ao crédito rural. Os bancos, por sua vez, são incentivados a conceder empréstimos ao agricultor, visto que o Governo equaliza o diferencial de juros, uma vez que, à taxa de juro de mercado, os produtores não tomariam o crédito e, se o fizessem, o risco de inadimplência associado ao empréstimo seria muito alto. Ademais, de acordo com Castro e Teixeira (2004), as instituições financeiras cobram um spread muito alto do Governo para participar do programa de ETJ, o que configura grande estímulo para emprestar os recursos ao produtor rural. 
restrições na compra ótima de insumos, de forma que uma política de subsídios via crédito rural exerça impactos positivos na produção ao disponibilizar maior volume de recursos para a aquisição de insumos.

Considerando esta hipótese, o objetivo deste trabalho consiste em avaliar as distorções setoriais provocadas pelo subsídio do crédito rural na economia das macrorregiões brasileiras, no intuito de investigar os efeitos de longo prazo da política sobre a produção, comércio externo e competitividade (via preços) do setor agropecuário.

Esses efeitos, no entanto, devem variar significativamente dependendo da commodity, dada a estrutura competitiva do mercado de cada uma delas, e, ainda, pelo fato de algumas culturas receberem maior montante de subsídio relativamente às demais. Nessas análises, um modelo de equilíbrio geral supera os modelos de equilíbrio parcial porque permite os exames setoriais, dada a interdependência entre as atividades. Como a política em questão é direcionada a uma atividade específica, a agropecuária, é preciso conhecer seus impactos sobre o próprio setor, bem como sobre os demais setores da economia, considerando que os setores e mercados são interligados e o efeito entre eles é sistêmico. Análises em equilíbrio parcial são provavelmente insuficientes no estudo de impacto de políticas setoriais. Ainda, tendo em vista que os recursos da ETJ e, consequentemente, do crédito rural, são concentrados entre as regiões brasileiras e que as economias dessas regiões apresentam estruturas heterogêneas, é importante levar em conta os impactos regionais da política.

Dessa forma, é empregado um Modelo Aplicado de Equilíbrio Geral para a análise empírica pretendida, especificamente o modelo do Projeto de Análise de Equilíbrio Geral da Economia Brasileira (PAEG), que apresenta a contribuição de modelar as regiões brasileiras e o relacionamento destas com o resto do mundo e tem uma desagregação relevante do setor agropecuário ${ }^{5}$.

5 Para mais informações sobre o PAEG, consultar Gurgel, Pereira e Teixeira (2012a). 
Este trabalho encontra-se dividido em mais três seções, além desta introdução. Na segunda seção, estão o referencial metodológico, que apresenta o modelo do PAEG, a fonte de dados e os cenários analíticos. Em seguida, na terceira seção, expõem-se os resultados. No quarto item, encontram-se as principais conclusões.

\section{Metodologia}

Segundo Jensen et al.(2010), modelos de equilíbrio geral, por considerarem as ligações intersetoriais, são os mais adequados para medir efeitos de políticas comerciais e intervencionistas, pois captam o efeito total (diretos e indiretos) que a política propicia. Assim, o referencial analítico que fundamenta a presente pesquisa é baseado na análise clássica de equilíbrio geral da economia. Utiliza-se o modelo do PAEG, que é capaz de representar as economias das grandes regiões brasileiras e países parceiros, bem como analisar os fluxos comerciais e de proteção ao comércio e, ainda, a aplicação de mudanças em variáveis de políticas sobre as regiões. As subseções a seguir descrevem a fundamentação analítica desta pesquisa e apresentam a fonte de dados e os cenários propostos.

\subsection{O Modelo do PAEG}

O modelo do PAEG é estático, multirregional e multissetorial, construído com vistas a analisar a economia brasileira de forma regional e integrada. Representa a produção e a distribuição de bens e serviços na economia mundial, em que cada região é representada por uma estrutura de demanda final e os agentes apresentam comportamento otimizador, maximizando seu bem-estar sujeito a uma restrição orçamentária, considerando fixos o investimento e a produção do setor público. Os setores produtivos combinam insumos intermediários e fatores primários de produção, com vistas a minimizar os custos, dada a tecnologia ${ }^{6}$.

6 Consultar Gurgel, Pereira e Teixeira (2012a). 
O PAEG é baseado no modelo e na base de dados do Global Trade Analysis Project (GTAP) 7 . Entretanto, adota-se a estrutura básica do modelo GTAPinGAMS (RUTHERFORD e PALTSEV, 2000; RUTHERFORD, 2005) que utiliza a sintaxe do Modeling Programing System for General Equilibrium (MPSGE), cujo ganho consiste na elaboração de um problema de complementaridade não-linear, em linguagem de programação GAMS.

A base de dados do PAEG é compatível com a base de dados do GTAP $7.0^{8}$. No entanto, no caso do PAEG, em vez de se trabalhar com um único país, Brasil, consideram-se as cinco grandes regiões brasileiras com dados compatíveis para o ano de 2004. Para tanto, torna-se necessário substituir os dados do Brasil obtidos de uma agregação do banco de dados do GTAP 7.0 pelos dados das matrizes de insumo-produto das macrorregiões brasileiras. Em tal substituição, os dados de fluxos comerciais entre o Brasil e as demais regiões do mundo são mantidos intactos. O primeiro passo consiste em preparar uma agregação, tanto dos dados do GTAP quanto das matrizes regionais brasileiras, para as regiões e setores de interesse de estudo. Posteriormente, ambos os dados são lidos em um mesmo arquivo e os dados das matrizes regionais brasileiras são reescalonados, de modo que o PIB da economia brasileira, formado pela soma dos PIB's das matrizes regionais, seja compatível, em magnitude, com o PIB do Brasil, na base de dados do GTAP. Os dados para as importações brasileiras são distribuídos entre as regiões, utilizando as matrizes regionais para definir a participação relativa das importações de cada região no total das importações brasileiras.

Esse mesmo procedimento é utilizado para distribuir regionalmente as exportações brasileiras na base de dados do GTAP. Dessa forma, os dados de exportações e importações originais das matrizes regionais brasileiras são substituídos pelos dados de fluxos comerciais do Brasil no GTAP. No entanto, as contas de oferta e demanda das matrizes regionais brasileiras perdem o equilíbrio, uma vez que seus dados originais de exportações e

7 Para mais informações sobre o GTAP, consultar Hertel (1997).

8 Para mais informações, consultar Gurgel, Pereira e Teixeira (2012b). 
importações foram substituídos pelos dados do Brasil no banco de dados do GTAP. A fim de recompor o equilíbrio, são ajustados os valores dos investimentos setoriais nas regiões brasileiras (formação bruta de capital), assim como os fluxos de capitais entre regiões. Esse procedimento evita o inconveniente de alterar coeficientes de insumo-produto dos setores em desequilíbrio. Por fim, as elasticidades para o Brasil contidas na base de dados do GTAP são atribuídas às regiões brasileiras, e os dados para o Brasil são retirados, restando apenas os dados das matrizes regionais brasileiras e das demais regiões do GTAP.

A base de dados do PAEG inclui os fluxos bilaterais de comércio entre países e regiões, bem como os custos de transporte, tarifas de importação e impostos ou subsídios às exportações. A Tabela 1 descreve o conjunto de dados representados no modelo.

Tabela 1 - Índices da base de dados

\begin{tabular}{ll}
\hline \multicolumn{1}{c}{ Índice } & \multicolumn{1}{c}{ Descrição } \\
\hline $\mathrm{i}, \mathrm{j}$ & Setores e bens \\
$\mathrm{r}, \mathrm{s}$ & Paises e regiões \\
$\mathrm{f} \in \mathrm{m}$ & Fatores de produção de livre mobilida de dentro de cada região e entre as \\
& regiões brasileiras: trabalho qualifica do e não-qualifica do e capital \\
$\mathrm{f} \in \mathrm{s}$ & Fatores de produção fixos: Terra e outros recursos naturais
\end{tabular}

Fonte: Gurgel et al.(2009).

O funcionamento do modelo PAEG pode ser demonstrado pelas identidades contábeis macroeconômicas, representadas pela matriz de contabilidade social. A equação (1) mostra que a produção doméstica ( vom $_{\mathrm{ir}}$ ) é distribuída entre exportações $\left(\mathrm{vxmd}_{\mathrm{irs}}\right)$, serviços de transporte internacional ( $\left.\mathrm{vst}_{\mathrm{ir}}\right)$, demanda intermediária $\left(\mathrm{vdfm}_{\mathrm{ijr}}\right)$, consumo privado $\left(\operatorname{vdpm}_{\mathrm{ir}}\right)$, investimento $\left(\operatorname{vdim}_{\mathrm{ir}}\right)$ e consumo do governo $\left(\operatorname{vdgm}_{\mathrm{ir}}\right)$. A equação (2) denota que bens importados, representados por vim ${ }_{\mathrm{i},}$, são utilizados no consumo intermediário $\left(\right.$ vifmj $_{\mathrm{ir}}$ ), no consumo privado (vi$\mathrm{pm}_{\mathrm{ir}}$ ) e no consumo do governo $\left(\right.$ vigm $\left._{\mathrm{ir}}\right)$. 


$$
\begin{aligned}
& \text { vom }_{\text {ir }}=\sum_{s} v_{x m d_{i r s}}+v s t_{i r}+\sum v d f m_{i j r}+v d p m_{i r}+v d g m_{i r}+v d i m_{i r} \\
& v_{i m} m_{i r}=\sum_{j} v i f m_{i j r}+v i p m_{i r}+v i g m_{i r}
\end{aligned}
$$

$\mathrm{Na}$ produção do bem $\mathrm{j}\left(\mathrm{Y}_{\mathrm{ir}}\right)$, incluem-se insumos intermediários (domésticos e importados) e fatores de produção móveis e específicos $\left(v_{f m}, f \in m\right)$. A renda dos fatores de produção é distribuída ao agente representativo. $\mathrm{O}$ equilíbrio nos mercados de fatores é dado por uma identidade que relaciona o valor do pagamento dos fatores com a sua renda, como expresso na equação (3).

$$
\sum_{i} v \mathrm{fm}_{f i r}=\text { evom }_{f r}
$$

O equilíbrio entre oferta e demanda requer que as exportações sejam iguais às importações (equação 4):

$$
v x m_{i r}=\sum_{s} v x m d_{i r s}
$$

Em que vxm $_{\text {ir }}$ representa as exportações do bem i pela região $r$ e vxmd ${ }_{\text {irs, }}$ as importações do mesmo bem pelos parceiros comerciais.

Do mesmo modo, a oferta agregada do serviço de transporte j é igual ao valor dos serviços de transporte nas exportações (equação 5):

$$
v t_{j}=\sum_{r} v s t_{j r}
$$

O equilíbrio entre oferta e demanda no mercado de serviços de transporte iguala a oferta desses serviços à soma dos fluxos bilaterais de serviços de transporte adquiridos nas importações de bens, como em (6):

$$
v t_{j}=\sum_{r} v t w r_{j i s r}
$$

A renda do governo $\left(\operatorname{vgm}_{\mathrm{r}}\right)$ consiste na soma dos impostos e transferências. Dessa forma, a restrição orçamentária do governo pode ser representada pela equação (7): 
$v g m_{r}=\sum_{i} R_{i r}^{Y}+R_{r}^{c}+R_{r}^{G}+\sum_{i} R_{i r}^{M}+R_{r}^{H H}+v b_{r}$

Em que $R_{i r}^{Y}, R_{r}^{c}, R_{r}^{G}, R_{i r}^{M}$ são os impostos indiretos na produção e exportação, sobre consumo, na demanda do governo e nas importações, respectivamente. ${ }^{R_{r}^{H H}}$ representa os impostos indiretos ao agente representativo e $v b_{r}$, as transferências do exterior.

A restrição orçamentária do agente representativo relaciona a renda dos fatores de produção $e^{e v o m_{f r}}$, descontada dos pagamentos de impostos $R_{r}^{H H}$, com as despesas de consumo $v p m_{r}$ e investimento privado vim $_{r}$ (relação 8):

$\sum_{f}$ evom $_{f r}-R_{r}^{H H}=v p m_{r}+\operatorname{vim}_{r}$

Assim, a partir das equações apresentadas, podem-se enumerar duas condições de equilíbrio: oferta igual à demanda e renda líquida igual à despesa líquida. No PAEG, assim como no GTAP, considera-se que a economia opere em competição perfeita e, dessa forma, as pressuposições clássicas são válidas: Retornos constantes à escala, custo de produção igual ao valor da produção, e, portanto, lucro econômico igual a zero. Essas condições se aplicam a cada um dos setores produtivos e atividades, conforme as equações de (9) a (14):

$$
\begin{aligned}
& Y_{i r}: \sum_{f} v f m_{f i r}+\sum_{j}\left(v i f m_{j i r}+v i f m_{j i r}\right)+R_{i r}^{Y}=v o m_{i r} \\
& M_{i r}: \sum_{s}\left(v x m d_{i s r}+\sum_{j} v t w r_{j i s r}\right)+R_{i r}^{M}=v i m_{i r} \\
& \left.C_{r}: \sum_{i} v d p m_{i r}+\operatorname{vipm}_{i r}\right)+R_{i r}^{C}=v p m_{r} \\
& I_{r}: \sum_{i} v \text { dim }_{i r}=v i m_{r}
\end{aligned}
$$




$$
\begin{aligned}
& F T_{f r}: \text { evom }_{f r}=\sum_{i} v f m_{f i r} f \in s ; e \\
& Y T_{j}: \sum_{r} v s t_{j r}=v t_{j}=\sum_{i r s} v t w r_{j i r s}
\end{aligned}
$$

O comportamento das firmas ${ }^{9}$ é otimizador e definido por funções de produção, sendo representado em blocos de produção (RUTHERFORD, 1999). A oferta das firmas é definida por um problema de otimização cujo objetivo é a minimização de custos unitários pela combinação de insumos primários de produção e insumos intermediários, sendo a cesta de insumos intermediários composta por bens domésticos e importados. A substituição entre os componentes do valor adicionado é representada por uma função Constant Elasticity of Substitution (CES). Já os insumos intermediários e primários são combinados a partir de uma função Leontief. Cada insumo intermediário nessa função Leontief é uma combinação entre uma parcela doméstica e importada de um determinado bem, a partir de uma função CES de elasticidade de substituição. Em relação à demanda por insumos importados, cada bem importado, demandado por uma região, é um agregado de bens importados de diferentes regiões do modelo. A escolha entre importações de diferentes parceiros comerciais é baseada na pressuposição de Armington.

O comportamento dos agentes consumidores também é otimizador, sendo representado por blocos de demanda. A demanda final no modelo é caracterizada por uma função Cobb-Douglas entre bens compostos, formados pela agregação de bens domésticos e importados. Já o consumo da administração pública é representado, no modelo, por uma agregação Leontief, composta por bens domésticos e importados. Terra e recursos naturais são considerados fatores específicos de produção, ofertados mediante uma função de elasticidade de transformação constante (CET).

9 Essa descrição é completa em Rutherford (2005). 


\subsection{Regra de fechamento}

A operacionalização de modelos de equilíbrio geral exige que sejam estabelecidas hipóteses de simulação, ou o conjunto de variáveis exógenas e endógenas, definindo o chamado "fechamento" do modelo. A definição destas hipóteses permite choques exógenos específicos, para determinadas variáveis, que desencadeiam alterações nas variáveis endógenas, por meio de mudanças nos preços relativos e quantidades reais, associadas ao horizonte de tempo hipotético das simulações, ou seja, ao período de tempo necessário para que a economia se mova rumo ao novo equilíbrio. $\mathrm{O}$ fechamento escolhido neste estudo é de longo prazo, de modo que são estabelecidas as seguintes hipóteses: oferta total de cada fator primário não se altera (exógena), no entanto, tais fatores são móveis entre os setores dentro de uma mesma região. No caso das regiões brasileiras, permite-se, ainda, a livre mobilidade de trabalho e capital entre elas ${ }^{10}$. Vale ressaltar que entre os países essa mobilidade não acontece. $\mathrm{O}$ fator terra é específico aos setores agropecuários, enquanto recursos naturais são específicos a alguns setores (de extração de recursos minerais e energia). Não há desemprego no modelo, portanto, os preços dos fatores são flexíveis (endógenos). Pelo lado da demanda, os investimentos e fluxos de capitais são mantidos fixos, bem como o saldo do balanço de pagamentos. Dessa forma, mudanças na taxa real de câmbio devem ocorrer para acomodar alterações nos fluxos de exportações e importações após os choques.

10 Reconhece-se a limitação dessa pressuposição, uma vez que é senso comum o fato de os fatores não migrarem livremente de uma região para outra, dados os custos econômicos e vários fatores de ordem subjetiva que impedem seu livre deslocamento. Contudo, é perfeitamente aceitável que exista um determinado nível de deslocamento em resposta a uma desigualdade em suas respectivas remunerações. Na ausência de estimativas quantitativas que permitam representar a segmentação dos mercados regionais de fatores produtivos e o grau de restrição à mobilidade desses fatores entre as regiões, acredita-se ser mais razoável supor que existe total mobilidade, uma vez que a suposição alternativa de ausência de mobilidade tornaria cada região brasileira como um "país" independente dos demais no modelo. 


\subsection{Base de dados}

A base de dados do GTAP 7.0 conta com matrizes Insumo-Produto (MIP) para 113 regiões, incluindo o Brasil, 57 setores e cinco fatores primários. Os dados do GTAP mostram o ambiente econômico para o ano de 2004 e as informações para o comércio internacional e doméstico ${ }^{11}$.

Para a elaboração do banco de dados do PAEG para as grandes regiões brasileiras, utilizou-se a Matriz Insumo-Produto (MIP) inter-regional de 1995, desagregada nas cinco macrorregiões do país, obtida por Parré (2000). A matriz inter-regional, no entanto, foi atualizada para o ano de 2004 e o setor agropecuário desagregado em 7 setores.

A atualização da MIP inter-regional iniciou-se pela obtenção da evolução do Valor Adicionado Bruto das grandes regiões e Estados por atividade econômica (INSTITUTO BRASILEIRO DE GEOGRAFIA E ESTATÍSTICA, 2007), de forma a obter as demandas finais regionais por produto, para o ano de 2004. Como não foram encontradas taxas de crescimento para todas as atividades econômicas, algumas delas (Metalurgia, Mecânica, Material Elétrico, Madeira e Mobiliário, Celulose Papel e Gráfica, Indústria da Borracha, Química, Farmacêutica, Plásticos, Indústria Têxtil, Vestuário e Calçados e Indústrias Diversas) foram obtidas residualmente, retirando-se da taxa de crescimento da demanda final regional a soma das outras taxas de crescimento existentes.

Considerando-se a hipótese de que os coeficientes técnicos da MIP mantenham-se fixos, é possível obter o vetor do Valor Bruto da Produção atualizado para o ano de 2004, na forma:

$$
X^{\prime}=[I-A]^{-1} \cdot Y^{\prime}
$$

em que $Y$ 'é o vetor de demanda final regional, atualizado para o ano de 2004; $A$ é a matriz dos coeficientes técnicos de 1995; obtendo X', que é o vetor de Valor Bruto da Produção para o ano de 2004.

11 Para mais detalhes sobre o banco de dados do GTAP 7.0, consultar Narayanan e Walmsley (2008). 
Para completar o procedimento de atualização da MIP, seu fechamento foi obtido pelo método de balanceamento do Quociente Locacional (QL), cujo detalhamento se encontra em Miller e Blair (2009).

Para a desagregação da agropecuária em sete atividades, utilizaram-se como base as MIP's da região Norte, elaborada por Guilhoto (2002) para o Banco da Amazônia (BASA), e da região Nordeste obtida por Azzoni et al. (2001). Para o Centro-Oeste, Sul e Sudeste utilizaram-se matrizes proxies, uma vez que não estavam disponíveis MIP's dessas macrorregiões. Para o Centro-Oeste, utilizou-se a matriz inter-regional do Estado do Mato Grosso obtida por Figueiredo (2003). Para o Sul, utilizaram-se as matrizes dos Estados do Paraná e do Rio Grande do Sul, obtidas por Nuñes e Kureski (2003) e pela Fundação de Economia e Estatística Siegfried Emanuel Heuser (FEE, 2002), respectivamente. Já para o Sudeste, baseou-se na matriz de consumo intermediário do Brasil, elaborada pelo IBGE (2007b). A escolha da matriz brasileira como proxy justifica-se pela pressuposição de que a estrutura produtiva do referido setor, para o Sudeste, aproxima-se da verificada no Brasil. Contribui também para essa aproximação o fato de grande parte da produção agropecuária nacional se concentrar nesta região. Uma descrição detalhada de todo o procedimento se encontra em Pereira e Teixeira (2009).

Para a obtenção dos fluxos comerciais entre as regiões brasileiras e outras regiões estrangeiras da agregação, foram utilizados os dados do Aliceweb (MINISTÉRIO DO DESENVOLVIMENTO, INDÚSTRIA E COMÉRCIO EXTERIOR, 2009); em seguida, estes dados foram compatibilizados com a base de dados 7.0 do GTAP.

A Tabela 2 apresenta a composição setorial e regional do PAEG. Para este estudo, a base de dados está desagregada em 19 setores, sendo 7 agrícolas, 7 industriais e 5 representantes do setor de serviços, e 12 regiões, entre elas as 5 macrorregiões brasileiras. 
Tabela 2 - Agregação entre regiões e setores para o Paeg

\begin{tabular}{ll}
\hline \multicolumn{1}{c}{ Regiões } & \multicolumn{1}{c}{ Atividades } \\
\hline 1-Brasil - regiao Norte (NOR) & 1-Arroz (pdr) \\
2-Brasil - região Nordeste (NDE) & 2-Milho e outros grãos (gro) \\
3-Brasil - região Centro-Oeste (COE) & 3-Soja e outras oleaginosas (osd) \\
4-Brasil-região Sudeste (SDE) & 4-Cana-de-açúcar, beterraba açuc., ind. Açúcar (c_b) \\
5-Brasil-região Sul (SUL) & 5-Carnes e animais vivos (oap) \\
6-Resto do Mercosul (MER) & 6-Leite e derivados (rmk) \\
7-Estados Unidos (USA) & 7-Outros produtos agropecuários (agr) \\
& 8-Produtos alimentares - Outros produtos alimentares, \\
8-Resto do Nafta (NAF) & bebidas e tabaco (foo) \\
9-Resto da América (ROA) & 9-Indústria Têxtil (tex) \\
10 -União Europeia 25 (EUR) & 10-Vestuário e calçados (wap) \\
11-China (CHN) & 11-Madeira e mobiliário (lum) \\
12-Resto do Mundo (ROW) & 12-Papel, celulose e ind. Gráfica (ppp) \\
& 13-Químicos, ind. Borracha e plásticos (crp) \\
& 14-Manufaturados: minerais não metálicos, metal \\
& mecânica, mineração, indústrias diversas (man) \\
& 15-SIUP e com. (siu) \\
& 16-Construção (cns) \\
& 17-Comércio (trd) \\
& 18-Transporte (otp) \\
& 19-Serviços e administração pública (ser) \\
&
\end{tabular}

Fonte: Elaboração própria.

Os dados para os gastos com a ETJ e o crédito rural total foram retirados da Secretaria do Orçamento Federal (SOF) (2010) e do Anuário Estatístico do Crédito Rural (BCB, 2004), respectivamente. Os dados para a ETJ na publicação supracitada estão agregados para o país, porém desagregados nas modalidades Agricultura Familiar e Agricultura Comercial. Já os dados para o crédito rural total são desagregados em culturas e regiões e nas modalidades Familiar e Comercial.

Para desagregar a ETJ dos subsídios totais pagos à agricultura, realizou-se uma partição aproximada da distribuição do gasto com a ETJ e do valor que ela proporciona em crédito para as culturas nas regiões, conforme a distribuição proporcional do crédito rural total nas mesmas. Esse procedimento foi realizado separadamente para a Agricultura Comercial e Agricultura Familiar. Apesar de não contar com os dados reais para a 
ETJ em cada cultura e região, acredita-se que esse procedimento tenha permitido obter boas proxies, uma vez que, segundo Bittencourt (2003), a ETJ garante a oferta de cerca de $70 \%$ dos recursos de crédito direcionado à Agricultura familiar e por volta de $30 \%$ daqueles direcionados à Agricultura comercial. Isto posto, considerar que os gastos com a ETJ, bem como o montante de crédito proporcionado por ela, se distribui conforme o crédito rural total é uma aproximação bastante razoável. $\mathrm{O}$ volume de crédito rural proporcionado pela ETJ para o Brasil como um todo foi calculado com base nos trabalhos de Bittencourt (2003) e Castro (2004). A partir da desagregação da ETJ dos subsídios totais pagos à agricultura na matriz do PAEG e do cálculo do montante de crédito rural proporcionado pelo subsídio, foi possível aplicar as simulações.

A análise de alguns indicadores da base de dados do modelo é importante para o melhor entendimento dos efeitos econômicos que serão simulados. A Tabela 3 mostra o VBP dos setores que compõem o modelo PAEG. Verifica-se que a maior parcela do VBP compete ao setor terciário (acima de $50 \%$ em todas as regiões), seguida pela indústria e agropecuária, em todas as macrorregiões.

Analisando primeiramente as colunas da Tabela 3, isto é, a composição do VBP de cada região, infere-se que: do VBP total da região Norte, 25,0\% compete à atividade de Serviços e Administração Pública e 23,0\% ao setor Manufaturados, que se destaca em função da Zona Franca de Manaus. Quando comparada aos demais setores, a agropecuária tem pouca representatividade em termos de valor da produção nesta região. No Nordeste, a atividade de Serviços e Administração Pública também é aquela de maior proporção no VBP da região $(32,4 \%)$, seguido pelos setores de Construção (16,5\%) e Comércio (10,0\%). A região CentroOeste, por sua vez, é aquela em que a atividade Serviços e Administração Pública detém participação mais expressiva na totalidade de seu VBP $(45,0 \%)$, devido, sobretudo, à presença do Distrito Federal entre os Estados que a compõe. No Centro-Oeste, os valores da produção da agropecuária e indústria mostram-se bem próximos, sendo que, entre as regiões do país, é aquela em que o setor agrícola mostra-se mais 
representativo em termos de VBP. No Sudeste, embora o setor terciário também adquira a maior parcela de seu $\operatorname{VBP}(51,6 \%)$, é a região em que a Indústria detém mais expressiva participação $(43,6 \%)$ e a agricultura menos $(4,8 \%)$ em relação às demais regiões do país. Por fim, no Sul destacam-se as atividades de Serviços de Administração Pública (28,2\%) e Produtos Alimentares (10,6\%), sendo que a última, ainda que tenha classificação industrial, possui forte encadeamento com o setor primário. Estes dados revelam, em último grau, a maior importância relativa da Agropecuária para as regiões Centro-Oeste, Sul e Nordeste em relação ao Sudeste e Norte.

Tabela 3 - Valor Bruto da Produção em 2004 (em R\$ bilhões)

\begin{tabular}{|c|c|c|c|c|c|c|}
\hline \multirow{2}{*}{ Setores } & \multicolumn{6}{|c|}{ Regiões } \\
\hline & NOR & NDE & COE & SDE & SUL & Total \\
\hline Total Agrope cuária & 5,78 & 17,25 & 18,08 & 41,37 & 39,02 & $\mathbf{1 2 1 , 5 0}$ \\
\hline 1-Arroz (pdr) & 0,05 & 0,67 & 1,13 & 1,17 & 2,42 & 5,44 \\
\hline 2-Milho e outros grãos (gro) & 0,24 & 1,00 & 0,42 & 2,15 & 2,63 & 6,44 \\
\hline 3-Soja e outras oleaginosas (osd) & 0,04 & 1,02 & 4,03 & 2,81 & 5,25 & 13,15 \\
\hline 4-Cana-de-açúcar, beterraba açuc., ind. Açúcar (c_b) & 0,08 & 4,26 & 0,51 & 2,33 & 1,75 & 8,94 \\
\hline 5-Carnes e animais vivos (oap) & 0,84 & 3,09 & 7,57 & 7,15 & 7,60 & 26,24 \\
\hline 6-Leite e derivados (rmk) & 0,11 & 0,34 & 0,54 & 2,60 & 1,52 & 5,11 \\
\hline 7-Outros produtos agropecuários (agr) & 4,43 & 6,86 & 3,87 & 23,15 & 17,86 & 56,17 \\
\hline Total Indústria & 25,76 & 47,51 & 19,29 & $\mathbf{3 7 6 , 5 3}$ & 136,10 & 605,20 \\
\hline 8-Produtos alimentares - Outros produtos alimentares, & 2,46 & 11,73 & 6,65 & 56,25 & 39,11 & 116,20 \\
\hline 9-Indústria Têxtil (tex) & 1,30 & 3,04 & 1,17 & 14,14 & 14,33 & 33,99 \\
\hline 10-Vestuário e calçados (wap) & 0,16 & 2,07 & 0,72 & 7,77 & 21,63 & 32,36 \\
\hline 11-Madeira e mobiliário (lum) & 1,41 & 0,93 & 0,80 & 5,27 & 7,96 & 16,37 \\
\hline 12-Papel, celulose e ind. Gráfica (ppp) & 1,06 & 0,90 & 1,10 & 18,21 & 6,12 & 27,40 \\
\hline 13-Químicos, ind. Borracha e plásticos (crp) & 2,90 & 17,55 & 5,54 & 93,67 & 15,33 & 134,99 \\
\hline 14-Manufaturados: minerais não metálicos, metal mecâ1 & 16,47 & 11,29 & 3,30 & 181,23 & 31,61 & 243,89 \\
\hline Total Serviços & 40,27 & 120,46 & 91,18 & 445,59 & 188,63 & 886,12 \\
\hline 15-SIUP e com. (siu) & 2,69 & 6,67 & 2,69 & 27,27 & 15,82 & 55,14 \\
\hline 16-Construção (cns) & 14,17 & 30,57 & 21,36 & 34,86 & 28,66 & 129,62 \\
\hline 17-Comércio (trd) & 4,51 & 17,95 & 7,37 & 52,59 & 24,94 & 107,36 \\
\hline 18-Transporte (otp) & 1,17 & 5,19 & 3,27 & 40,70 & 16,66 & 66,99 \\
\hline 19-Serviços e administração pública (ser) & 17,73 & 60,08 & 56,49 & 290,17 & 102,55 & 527,02 \\
\hline Total & 71,81 & 185,22 & 128,55 & 863,48 & 363,75 & 1612,82 \\
\hline
\end{tabular}

Fonte: Elaboração própria a partir dos dados do Paeg

Nota: ${ }^{1}$ Regiões - Norte (NOR); Nordeste (NDE); Centro-Oeste (COE); Sudeste (SDE); Sul (SUL)

Quando se analisam as linhas da Tabela 3, isto é, a composição do VBP setorial do país, verifica-se que as regiões Sudeste e Sul respondem juntas por $66,17 \%$ de todo o VBP agrícola, sendo que a primeira é responsável pela metade do VBP da atividade de Leite e Derivados 
brasileira e a segunda por aproximadamente metade do VBP do setor de Arroz. Na indústria, apenas o Sudeste é responsável por $62,2 \%$ de seu VBP, sendo que na atividade de Manufaturados (que inclui metalurgia e afins e indústrias diversas) a região detém mais de $70 \%$ de todo o valor da produção, sendo ainda responsável pela metade do VBP do setor terciário de todo o país.

Ainda de acordo com a Tabela 3, pode-se inferir a relevância da agropecuária para o Centro-Oeste e Nordeste, uma vez que esse setor é aquele em que essas regiões mostram-se mais representativas em termos do VBP nacional, quando comparado à participação das mesmas na Indústria e Serviços. Em termos agregados, verifica-se a preponderância econômica da região Sudeste, que detém mais de 50\% de todo o valor da produção nacional.

A Tabela 4 mostra o montante de recursos disponibilizados sob a forma de crédito rural pela ETJ e sua respectiva participação no VBP dos setores agropecuários. Em termos do recebimento de crédito, nos extremos estão as regiões Sul, que recebeu em 2004 o maior volume, e a Norte, com o menor montante. Entre os setores, destacam-se Milho e outros grãos e Soja e outras oleaginosas na região Sul, que receberam a maior quantia de crédito via ETJ; Outros produtos agropecuários no Sudeste, e Soja e outras oleaginosas no Centro-Oeste também receberam montantes mais expressivos.

O setor Milho e outros grãos é aquele em que o crédito disponibilizado pela ETJ apresenta maior participação no seu VBP nas regiões Sul, Sudeste e Centro-Oeste. No Nordeste, o setor Leite e derivados é o mais subsidiado em relação ao seu valor da produção, e, no Norte, as atividades de Arroz e Soja e outras oleaginosas são aquelas de maior relação créditoVBP, tendo em vista a ínfima produção dessas commodities nesta região. 
Tabela 4 - Recurso disponibilizado em crédito rural pela ETJ e participação no VBP dos setores agropecuários em 2004

\begin{tabular}{lccccc}
\hline \multirow{2}{*}{ Setores } & \multicolumn{5}{c}{ Regiões } \\
\cline { 2 - 6 } & ROR & NDE & COE & SDE & SUL \\
\hline \multirow{2}{*}{ Recurso disponibilizado em crédito rural pela ETJ (em R $\$$ milhões) } \\
1-Arroz (pdr) & 21,15 & 18,78 & 38,19 & 13,06 & 172,34 \\
2-Milho e outros grãos (gro) & 10,61 & 50,60 & 118,38 & 221,68 & 767,32 \\
3-Soja e outras oleaginosas (osd) & 17,66 & 39,17 & 327,25 & 81,77 & 571,36 \\
4-Cana-de-açúcar, beterraba açuc., ind. Açúcar (c_b) & 0,12 & 18,87 & 3,61 & 108,89 & 6,97 \\
5-Carnes e animais vivos (oap) & 97,36 & 120,34 & 224,61 & 215,42 & 184,22 \\
6-Leite e derivados (rmk) & 20,53 & 28,76 & 42,40 & 100,39 & 44,64 \\
7-Outros produtos agropecuários (agr) & 58,90 & 177,89 & 117,92 & 446,30 & 294,25 \\
Total & 226,32 & 454,40 & 872,35 & 1187,51 & 2041,10 \\
\hline Recurso disponibilizado em crédito rural pela ETJ em relação ao VBP dos & setores agrícolas (em \%) \\
1-Arroz (pdr) & 43,66 & 2,78 & 3,39 & 1,11 & 7,12 \\
2-Milho e outros grãos (gro) & 4,47 & 5,08 & 27,94 & 10,32 & 29,15 \\
3-Soja e outras oleaginosas (osd) & 39,40 & 3,84 & 8,13 & 2,91 & 10,89 \\
4-Cana-de-açúcar, beterraba açuc., ind. Açúcar (c_b) & 0,15 & 0,44 & 0,70 & 4,67 & 0,40 \\
5-Carnes e animais vivos (oap) & 11,63 & 3,89 & 2,97 & 3,01 & 2,43 \\
6-Leite e derivados (rmk) & 19,10 & 8,35 & 7,83 & 3,85 & 2,94 \\
7-Outros produtos agropecuários (agr) & 1,33 & 2,59 & 3,05 & 1,93 & 1,65 \\
Total & 3,91 & 2,63 & 4,83 & 2,87 & 5,23 \\
\hline
\end{tabular}

Fonte: Elaboração própria a partir dos dados do Paeg

Nota: ${ }^{1}$ Regiões - Norte (NOR); Nordeste (NDE); Centro-Oeste (COE); Sudeste (SDE); Sul (SUL)

\subsection{Cenário analítico}

Para se avaliar os efeitos diretos e indiretos da política de ETJ sobre a produção setorial, é preciso estabelecer um choque que a elimine, no intuito de comparar uma situação sem a política com uma situação em que a mesma esteja presente.

Para implementar esse choque, é necessário, primeiro, eliminar todo o gasto governamental com a política na forma de subsídio à produção e, segundo, todo o montante de crédito que o subsídio proporciona ao ambiente econômico e comparar os resultados com o equilíbrio inicial. 
Este segundo choque faz-se necessário, uma vez que para representar o efeito total da eliminação da ETJ é preciso considerar não apenas a retirada do subsídio, mas também a redução no volume de crédito disponibilizado como consequência da equalização.

Assim como em Castro (2004), por simplificação, considera-se que o produtor gasta todo o recurso de crédito na compra de insumos intermediários. Em outro trabalho, Castro e Teixeira (2010) mensuraram a elasticidade de demanda por insumos em relação ao crédito rural para o Brasil e encontraram uma elasticidade de 0,95 para fertilizantes, isto é, muito próxima de 1. Esse resultado pode ser visto, em certa medida, como um respaldo empírico à consideração de que todo o financiamento adquirido pelo produtor é gasto com insumos intermediários.

Operacionalmente, promove-se um choque na variável subsídio à produção para as atividades do setor agropecuário, eliminando toda a parcela correspondente à ETJ e, ao mesmo tempo, elimina-se toda a compra de insumos intermediários à agricultura que o volume de crédito disponibilizado pelo subsídio proporciona.

Nesta segunda parte, implementa-se um choque homogêneo sobre os impostos ao consumo intermediário daqueles setores com os quais a agricultura está diretamente interligada. Isto é, como o objetivo da simulação é eliminar todo o efeito proporcionado pela ETJ para comparar com o equilíbrio inicial em que a política está presente no ambiente econômico, aumentam-se os impostos ao consumo intermediário do setor agrícola até que se observe queda na compra de insumos desse setor equivalente ao montante de crédito subsidiado.

Cabe destacar, no entanto, alguns inconvenientes do choque sobre os impostos ao consumo intermediário: 1) o aumento dos impostos provoca mudanças em preços relativos e, assim, a agricultura passa a enfrentar maiores preços no consumo intermediário em relação à indústria ou serviços; 2) o choque não permite especificar para cada produto agrícola a redução nos gastos devidos à remoção da ETJ, apenas permite simular a redução nos gastos com insumos intermediários de toda a agricultura, 
em cada região brasileira, pelo mesmo montante de queda dos recursos disponibilizados pela ETJ; e 3) mudança na arrecadação do governo devido diretamente à alteração nas alíquotas e indiretamente às variações no nível de atividade econômica. No entanto, diante das limitações de simular a queda direta na compra de insumos intermediários consequentes da eliminação da ETJ, acredita-se que a simulação proposta, apesar desses inconvenientes, seja uma alternativa razoável de representação dos efeitos da política.

Deve-se ressaltar que como o objetivo da simulação é avaliar os impactos setoriais da política de ETJ sobre a economia, os resultados são apresentados de forma contrária (com sinal trocado), isto é, qual efeito a política gera nas economias regionais e não a implicação de sua retirada. Ao inverter o sinal do resultado, permite-se estabelecer o impacto gerado pela política sobre as variáveis endógenas do modelo em uma situação em que a política é implementada. Desta forma, pode-se dizer que os resultados constituem desvios em relação ao cenário base, ou seja, representam as alterações no comportamento econômico das regiões brasileiras a partir de mudanças exógenas, no caso deste trabalho, desencadeadas por meio da incorporação do subsídio do crédito rural.

\section{Resultados}

Este trabalho considera a hipótese de que todo o montante de crédito rural subsidiado pela ETJ é aplicado na produção agropecuária via aquisição de insumos. Dessa forma, a política exercerá efeitos sobre a produção, comércio externo e preços dos produtos agropecuários brasileiros. Por outro lado, um estímulo a um setor pode representar um desestímulo a outro, tendo em vista a competição por fatores produtivos, de modo que a análise setorial desses efeitos é relevante.

A Tabela 5 aponta, de maneira geral, que o volume de recursos disponibilizados sob a forma de crédito rural mediante o gasto em 
equalizações promove, no longo prazo, expansão no valor da produção e das exportações na grande maioria das atividades agropecuárias de todas as regiões, em relação a um cenário sem a política. Em contrapartida, observam-se quedas na maioria dos setores de manufaturados e serviços, à exceção de algumas atividades, principalmente aquelas que detêm maiores ligações intersetoriais (a montante ou a jusante) com a agricultura. Quando se comparam os resultados para as variações no valor produzido e no valor exportado apresentados na Tabela $5 \mathrm{com}$ as variações do retorno ao capital e massa salarial pagos em cada setor (Tabela A1 em anexo), verifica-se o mesmo padrão, isto é, as atividades que apresentam expansões no valor produzido e, por conseguinte, no exportado, são aquelas que mostram variações positivas para os fatores produtivos.

$\mathrm{Na}$ região Norte, verifica-se que a política de ETJ tende a promover variações positivas expressivas no valor da produção e no valor das exportações de todos os setores agrícolas, com destaque para as atividades arroz (pdr), milho e outros grãos (gro) e soja e demais oleaginosas (osd) (Tabela 5). Cabe ressaltar que se trata de culturas pouco exploradas na região e, desse modo, a maior variação percentual apenas sinaliza a pequena magnitude desses setores no equilíbrio inicial do modelo. Uma outra forma de se pensar é que, tendo em vista a pequena representatividade desses setores na região, a ETJ representa papel bastante relevante, podendo dizer que os produtores que se inserem nessas atividades dependem fortemente do subsídio para adquirir insumos. Apenas o setor de cana-de-açúcar apresentou comportamento distinto dos demais setores agropecuários, mostrando redução no valor da produção e das exportações mediante a política de ETJ, que certamente ocorreu devido às distorções causadas pela maior produção de arroz e grãos possibilitada pelo subsídio. Quanto ao valor das importações, as atividades arroz ( $\mathrm{pdr}$ ), leite e derivados ( $\mathrm{rmk}$ ) e outros produtos agrícolas (agr) tiveram quedas, ao passo que as demais atividades agropecuárias apresentaram expansões. 


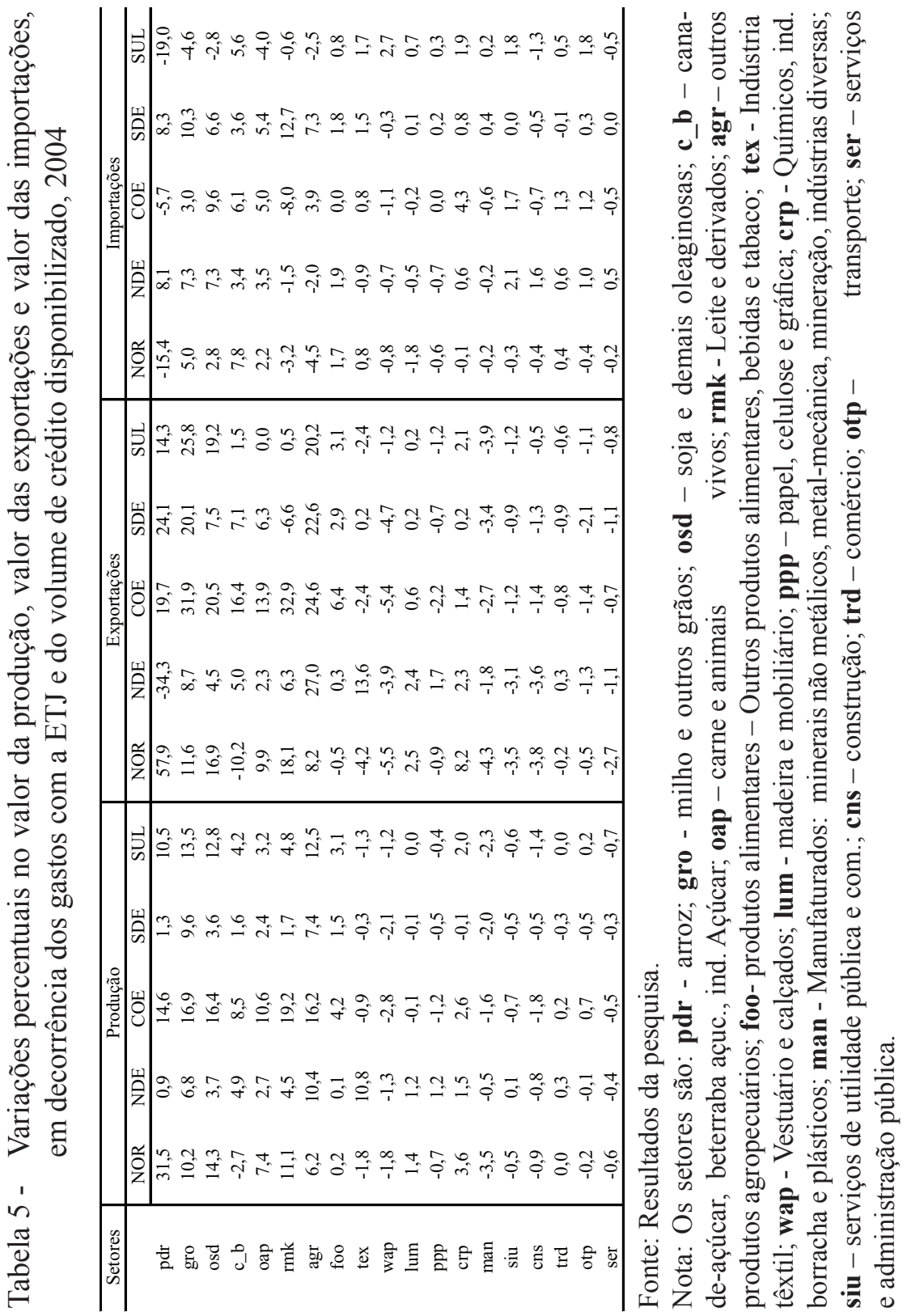


Os setores ligados à indústria e serviços da região Norte tendem a apresentar reduções no valor da produção e das exportações, à exceção das atividades indústria de alimentos (foo), madeira e mobiliário (lum) e químicos, indústria da borracha e plásticos (crp). Essas atividades apresentam expressiva interdependência com o setor agrícola, seja como demandantes de seus produtos, caso da indústria de alimentos (foo) e da atividade de madeira e mobiliário (lum), seja como ofertantes de insumos agropecuários (fertilizantes e defensivos), como o setor de químicos, indústria da borracha e plásticos (crp). Assim, o maior volume de recursos disponibilizados pelas equalizações permite aos produtores agrícolas: i) adquirir maior quantidade de insumos, o que afeta positivamente a indústria química; e ii) ofertar maior quantidade de produto, o que, ao reduzir seu preço, aumenta o nível de atividade dos setores a jusante. Entre os setores que apresentaram redução no valor da produção, destacam-se a atividade de manufaturados, que engloba as atividades industriais em geral, ao mostrar a maior queda percentual, tanto no valor da produção (3,45\%), quanto no valor das exportações $(4,29 \%)$. Esses resultados evidenciam a distorção que o subsídio causa ao padrão de competitividade dessa região, fazendo com que se reduza a produção daqueles bens nos quais apresenta maiores vantagens comparativas, para produzir, devido ao incentivo, os produtos agrícolas.

Na região Nordeste verifica-se expansão no valor da produção e das exportações de todos os setores agrícolas mediante a política de ETJ, à exceção do valor das exportações da atividade arroz (pdr). As maiores variações percentuais competiram às atividades milho e outros grãos (gro) e outros produtos agrícolas (agr), que abrangem, além de outros produtos, o setor de frutas, atividade bastante dinâmica na região. Em relação aos setores de manufaturados e de serviços, as mudanças ora foram negativas, ora positivas, caso da indústria têxtil (tex), que apresentou expansão significativa tanto no valor produzido (10,8\%), quanto no exportado $(13,6 \%)$. Essa atividade detém expressiva ligação para trás com o setor agrícola e constitui um segmento bastante representativo para a região, mostrando-se altamente dinâmica em anos mais recentes. Campos (2006) salienta que, nos últimos anos, o Nordeste é a região brasileira que vem 
apresentando o maior crescimento em todos os segmentos da indústria têxtil.

O estudo de Coronel (2010), ao verificar os efeitos da Política de Desenvolvimento Produtivo (PDP) sobre as atividades industriais brasileiras, mostrou que, quando se desoneraram essas atividades, a indústria têxtil, ao contrário das demais, respondeu negativamente frente aos incentivos recebidos. Esse resultado salienta que o estímulo relativo concedido às atividades industriais desestimula (relativamente) o setor agropecuário, e como a indústria têxtil depende fortemente desse setor, ela recebe os efeitos negativos decorrentes de altas nos preços, por exemplo. Assim, no estudo desse autor, os efeitos indiretos oriundos do desestímulo ao setor agrícola superaram os efeitos diretos decorrentes da desoneração tributária no setor. Dessa forma, no presente estudo, o contrário pode ser concluído para a região Nordeste, isto é, o subsídio ao setor agrícola provoca efeitos positivos na produção da indústria têxtil por conta dos efeitos indiretos.

No total, infere-se que os ganhos decorrentes do estímulo às atividades agropecuárias no Nordeste, atividades com maiores vantagens comparativas nessa região, tendem a superar a retração no valor da produção e das exportações de algumas poucas atividades industriais e de serviços.

No que compete à região Centro-Oeste, observa-se uma tendência de expressivo ganho no valor da produção e das exportações das atividades agrícolas, principalmente em seus segmentos mais característicos, como milho e outros grãos (gro), soja e demais oleaginosas (osd), leite e derivados (rmk) e outros produtos agrícolas (agr). O maior nível de renda e a demanda mais aquecida também possibilitam expansões representativas nas importações das atividades agrícolas (exceto leite e derivados) e em algumas atividades manufatureiras. Dentre essas, destacaram-se as compras no mercado externo para o setor de químicos, indústria da borracha e plástico (crp), que apresentaram aumento para atender à maior demanda em decorrência da expansão na produção agrícola, motivada pelo maior volume 
de recursos para adquirir insumos. Entre as atividades de manufaturados e serviços, a indústria de alimentos (foo) e o setor de químicos, indústria da borracha e plásticos (crp) foram os mais impactados positivamente pela ETJ no que compete ao valor da produção. Cabe também destacar o resultado do valor da produção para o setor de transportes (otp), que experimentou a maior variação percentual positiva entre todas as regiões, evidenciando a expressiva dependência do Centro-Oeste no que tange aos serviços de transporte. Dessa forma, infere-se que, dado o expressivo potencial agrícola dessa região, o estímulo oriundo da maior disponibilidade de recursos para adquirir insumos potencializa a produção, atraindo fatores produtivos de outras regiões, incentivando expressivamente a produção e a exportação agropecuária.

O Sudeste, por sua vez, apesar de apresentar ganhos no valor da produção dos setores agrícolas, experimenta queda nessa mesma variável em praticamente todas as atividades industriais e de serviços (à exceção da indústria alimentícia). $\mathrm{O}$ valor das exportações seguiu padrão parecido. Portanto, assim como na região Norte, a distorção setorial que o subsídio causa desestimula mais as atividades cuja região tem maiores vantagens comparativas, isto é, a indústria e os serviços, do que estimula a agropecuária.

Finalmente, a região Sul apresenta expansões mais relevantes no valor da produção e das exportações nas atividades arroz (pdr), outros produtos agrícolas (agr), naquelas ligadas ao setor de grãos (gro e osd) e na indústria alimentícia (foo). Para o valor das importações, observa-se queda na maioria das commodities agrícolas, sobretudo no setor arroz (pdr), sinalizando que a política de ETJ, ao expandir a produção agrícola nessa região, pode reduzir a necessidade de importar alimentos de outros mercados.

Em relação aos efeitos da política de ETJ sobre os preços domésticos e importados, a Tabela 6 apresenta as variações percentuais dos mesmos. Em linhas gerais, verifica-se que a política de subsídio do crédito rural tende a promover reduções nos preços domésticos dos alimentos em todas as regiões, principalmente nas atividades: arroz (pdr), nas regiões Norte, 
Centro-Oeste e Sul; milho e outros grãos (gro), nas regiões Centro-Oeste e Sul; soja e demais oleaginosas (osd), nas regiões Norte, Centro-Oeste e Sul; cana-de-açúcar (c_b), nas regiões Centro-Oeste e Sudeste; Carne e animais vivos (oap), nas regiões Norte e Centro-Oeste; leite e derivados (rmk), nas regiões Norte e Centro-Oeste; e outros produtos agrícolas (agr), nas regiões Centro-Oeste e Sul. A indústria de alimentos (foo) também apresenta queda no preço doméstico nas regiões brasileiras, sobretudo no Centro-Oeste e Sul, ao passo que as outras atividades ligadas aos setores de manufaturados e de serviços apresentam, em sua maioria, pequenas elevações.

Quanto ao preço dos importados, o padrão é semelhante aos preços domésticos, isto é, observa-se queda nos preços agrícolas e alta nos preços dos produtos de cunho manufatureiro e de serviços. Porém, vale destacar, que as reduções sobre os preços domésticos das commodities agropecuárias são sensivelmente superiores àquelas observadas para os mesmos produtos importados, evidenciando que o subsídio do crédito rural traz ganho de competitividade (via preços) para os produtos agropecuários nacionais frente aos estrangeiros. 
Tabela 6 - Variações percentuais nos preços domésticos e dos importados em decorrência da política de ETJ, 2004

\begin{tabular}{c|ccccc|ccccc}
\hline \multirow{2}{*}{ Setores* } & \multicolumn{5}{|c|}{ Preços domésticos } & \multicolumn{5}{c}{ Preços Importados } \\
\cline { 2 - 11 } & NOR & NDE & COE & SDE & SUL & NOR & NDE & COE & SDE & SUL \\
\hline pdr & $-19,9$ & $-7,0$ & $-14,3$ & $-10,4$ & $-13,3$ & $-9,2$ & $-8,7$ & $-8,2$ & $-12,8$ & $-5,0$ \\
gro & $-12,4$ & $-7,6$ & $-28,1$ & $-11,8$ & $-23,1$ & $-9,4$ & $-11,6$ & $-13,1$ & $-18,9$ & $-7,3$ \\
osd & $-10,0$ & $-2,9$ & $-8,9$ & $-4,9$ & $-9,6$ & $-6,8$ & $-7,3$ & $-6,6$ & $-9,0$ & $-3,8$ \\
c_b & $-4,9$ & $-7,8$ & $-10,7$ & $-8,1$ & $-7,3$ & $-7,8$ & $-7,7$ & $-7,5$ & $-7,8$ & $-7,6$ \\
oap & $-10,4$ & $-6,9$ & $-13,2$ & $-6,8$ & $-7,6$ & $-7,3$ & $-7,7$ & $-6,7$ & $-10,0$ & $-7,0$ \\
rmk & $-12,1$ & $-10,0$ & $-16,0$ & $-7,1$ & $-9,8$ & $-8,2$ & $-8,2$ & $-8,3$ & $-12,0$ & $-7,7$ \\
agr & $-7,3$ & $-9,6$ & $-11,9$ & $-7,0$ & $-10,9$ & $-3,1$ & $-5,5$ & $-6,9$ & $-8,9$ & $-5,0$ \\
foo & $-0,2$ & $-0,3$ & $-1,9$ & $-0,8$ & $-1,3$ & $-0,9$ & $-1,0$ & $-0,8$ & $-1,2$ & $-0,5$ \\
tex & 0,5 & $-2,2$ & 0,3 & $-0,1$ & 0,2 & 0,0 & 0,1 & $-0,1$ & $-0,5$ & $-0,4$ \\
wap & 0,8 & 0,7 & 0,8 & 0,8 & 0,8 & 0,8 & 0,7 & 0,7 & 0,7 & 0,0 \\
lum & $-0,5$ & $-0,5$ & $-0,1$ & $-0,1$ & $-0,2$ & $-0,2$ & $-0,1$ & $-0,2$ & $-0,2$ & $-0,3$ \\
ppp & 0,2 & $-0,4$ & 0,4 & 0,2 & 0,3 & 0,1 & 0,2 & 0,2 & 0,0 & 0,1 \\
crp & $-1,3$ & $-0,3$ & $-0,1$ & 0,2 & $-0,1$ & 0,1 & 0,1 & 0,1 & $-0,1$ & 0,1 \\
man & 0,7 & 0,4 & 0,5 & 0,5 & 0,7 & 0,3 & 0,4 & 0,5 & 0,1 & 0,3 \\
siu & 0,6 & 0,6 & 0,6 & 0,6 & 0,6 & 0,5 & $-0,1$ & 0,0 & 0,4 & $-0,1$ \\
cns & 1,0 & 0,9 & 1,0 & 0,9 & 0,9 & 0,7 & 0,0 & 0,6 & 0,9 & 0,9 \\
trd & 0,6 & 0,5 & 0,7 & 0,6 & 0,7 & 0,5 & 0,5 & 0,5 & 0,5 & 0,4 \\
otp & 0,5 & 0,6 & 0,6 & 0,6 & 0,6 & 0,4 & 0,4 & 0,3 & 0,3 & 0,1 \\
ser & 0,7 & 0,7 & 0,5 & 0,6 & 0,7 & 0,6 & 0,4 & 0,5 & 0,5 & 0,5 \\
\hline
\end{tabular}

Fonte: Resultados da pesquisa.

Nota:*Os setores são: pdr - arroz; gro - milho e outros grãos; osd - soja e demais oleaginosas; c_b - cana-de-açúcar, beterraba açuc. ind. Açúcar; oap - carne e animais vivos; rmk - Leite e derivados; agr - outros produtos agropecuários; foo- produtos alimentares - Outros produtos alimentares, bebidas e tabaco; tex - Indústria têxtil; wap - Vestuário e calçados; lum - madeira e mobiliário; ppp - papel, celulose e gráfica; crp - Químicos, ind. borracha e plásticos; man Manufaturados: minerais não metálicos, metal-mecânica, mineração, indústrias diversas; siu - serviços de utilidade pública e com.; cns - construção; trd comércio; otp - transporte; ser - serviços e administração pública.

Em suma, verifica-se que, na maioria dos setores agrícolas, o volume de recursos disponibilizados por meio da ETJ traz importantes contribuições à sua maior inserção no mercado interno e externo, porém, tendo em vista a diferença no padrão relativo de vantagens comparativas que essas regiões apresentam, o recurso distorce a produção e, consequentemente, o fluxo comercial e os preços, fazendo com que alguns setores se apresentem em situação relativamente pior do que num cenário mais liberal (sem o subsídio). 


\section{Considerações Finais}

O presente trabalho buscou trazer contribuições ao debate sobre a intervenção estatal por meio de políticas agrícolas na economia. Especificamente, objetivou aferir os efeitos da política de Equalização das Taxas de Juros do Crédito Rural (ETJ), implementada pelo Governo Federal, sobre a produção, o comércio externo e a competitividade (via preços) do setor agropecuário para as macrorregiões brasileiras, bem como avaliar as distorções na produção setorial que essa política promove. Para isso, utilizaram-se o modelo, o banco de dados e o software do Projeto de Análise de Equilíbrio Geral da Economia Brasileira (PAEG).

Os resultados mostram que a política de subsídio do crédito rural tem representado um importante papel de estímulo a toda a cadeia do agronegócio brasileiro, tendo em vista os impactos positivos sobre a produção e exportações da agropecuária, e mesmo a expansão das indústrias com forte interdependência com o setor agrícola, como químicos, indústria de alimentos e transportes. Ainda, a política está associada a ganho de competitividade (via preços) das commodities agropecuárias nacionais no mercado externo, já que tende a promover um maior diferencial entre preços internos e externos.

Cabe ressaltar, entretanto, que a atividade manufatureira em geral é relativamente desestimulada pela política. Esse desestímulo pode ser mais preocupante nas regiões onde o setor industrial possui maiores vantagens comparativas em relação ao setor agrícola, caso do Norte e Sudeste. Nessas regiões, os benefícios econômicos provenientes do estímulo ao setor agropecuário tendem a ser superados pelos resultados negativos no setor industrial, o que certamente conduz a resultados econômicos piores.

Todavia, pode-se dizer que esta política agrícola se mostra eficiente quanto a seu propósito de corrigir a falha de mercado associada aos riscos e maior vulnerabilidade a condicionantes exógenos enfrentada no setor agrícola. 


\section{Referências}

ARAÚJO, P. F. C.; MEYER, R. L. Política de crédito rural no Brasil: objetivos e resultados. In: VEIGA, A. Ensaios sobre política agrícola brasileira. São Paulo: SA, 1979, pag. 137-162.

AZZONI, C. R.; KADOTA, D. K.; HADDAD, E. A.; RODRIGUES, M. T. Macroeconomia do Nordeste. Fortaleza: BNB, 2001.

BANCO CENTRAL DO BRASIL (BCB). Anuário estatístico do crédito rural - 2004. Brasília: $\mathrm{BCB}, 2006$. Disponível em: $<$ http://www. bcb.gov.br/?RELRURAL2004>. Acesso em: 18 mai. 2010.

BANCO DO BRASIL. Evolução Histórica do Crédito Rural. Revista de Política Agrí́cola. Ano XIII, n.4, Out./Nov./Dez., 2004. p. 10 a 17.

BITTENCOURT, G.A. Abrindo a caixa preta - o financiamento da agricultura familiar no Brasil. Campinas: UNICAMP, 2003. 213 p. Dissertação (Mestrado em Desenvolvimento Econômico, Espaço e Meio Ambiente) - Universidade Estadual de Campinas, 2003.

CASTRO, E. R. Efeitos dos gastos com a equalização das taxas de juros do crédito rural na economia brasileira. Viçosa: UFV, 2004. 82 p. Dissertação (Mestrado em Economia Aplicada) - Universidade Federal de Viçosa, 2004.

CASTRO, E. R.; TEIXEIRA, E. C. Retorno dos gastos com a equalização das taxas de juros do crédito rural na economia brasileira. Revista de Política Agrí́cola, ano 3, n. 3, p. 52 a 57, Jul./Ago./Set. 2004.

CASTRO, E. R. Crédito Rural e Oferta Agrícola no Brasil. UFV: 2008. 112 p. Tese (Doutorado em Economia Aplicada) - Universidade Federal de Viçosa, 2008.

CASTRO, E. R. ; TEIXEIRA, E. C. Crédito Rural e Oferta Agrícola no Brasil. Revista de Política Agrícola, v. XIX, p. 9-16, 2010. 
CASTRO, E. R. ; TEIXEIRA, E. C. Rural credit and agricultural supply in Brazil. Agricultural Economics, 43, 2012, p. 293-301.

CARVAlho, M. A. Políticas públicas e competitividade da agricultura. Revista de Economia Política, vol. 21, n.1 (81), jan$\operatorname{mar} / 2001$.

CORONEL, D. A. Impactos da Política de Desenvolvimento Produtivo na Economia Brasileira. Viçosa: UFV, 2010. 103 p. Tese (Doutorado em Economia Aplicada) - Universidade Federal de Viçosa, 2010.

FIGUEIREDO, M. G. Agricultura e estrutura produtiva do Estado do Mato Grosso: uma análise de insumo-produto. Piracicaba: ESALQ/ USP, 2003. 187 p. Dissertação (Mestrado em Economia Aplicada) Escola Superior de Agricultura Luiz de Queiroz, Universidade de São Paulo, Piracicaba, 2003.

GONÇALVES NETO, W. Estado e agricultura no Brasil: Política agrícola e modernização econômica brasileira 1960-1980. São Paulo: Hucitec, 1997.

GUILHOTO, J. J. M. Projeto de Estimação de Matrizes de InsumoProduto para a Região e os Estados da Amazônia Legal. Belém: Banco da Amazônia (BASA), 2002.

GURGEL, A.C.; PEREIRA, M.W.G.; TEIXEIRA, E.C. A estrutura do PAEG. PAEG Technical Paper, nº ${ }^{\circ}$, Viçosa: DER/UFV, 14 p., 2009.

GURGEL, A.C.; PEREIRA, M.W.G.; TEIXEIRA, E.C. A Estrutura do PAEG. PAEG Technical Paper (1): 1-14. In: IV Minicurso sobre o PAEG, 18 a 21/12/2012,UFV, Viçosa, MG, 2012.

GURGEL, A.C.; PEREIRA, M.W.G.; TEIXEIRA, E.C. A Base de Dados do PAEG. PAEG Technical Paper, nº. 3, Viçosa: DER/UFV, 12p., 2012.

HERTEL, T. W. (ed.). Global trade analysis: modeling and applications. Cambridge: Cambridge University Press, 1997. 
INSTITUTO BRASILEIRO DE GEOGRAFIAE ESTATÍSTICA(IBGE). Contas regionais do Brasil: Matriz Insumo-Produto brasileira - 1996. Rio de Janeiro: IBGE, 2006. Disponível em: <http://ftp.ibge.gov.br/ Contas_Nacionais/Matriz_de_Insumo_e_Produto/1996/>. Acesso em: 14 set. 2007.

INSTITUTO BRASILEIRO DE GEOGRAFIA E ESTATÍSTICA(IBGE). Contas regionais do Brasil: Por atividade econômica. Rio de Janeiro: IBGE, 2007. Disponível em: <http://www.ibge.gov.br/home/estatistica/ economia/contasregionais/2004/tabela07.pdf>. Acesso em: 14 set. 2007.

JENSEN, H. T.; ROBINSON, S.; TARP, F. Measuring agricultural policy bias: General equilibrium analysis of fifteen developing countries. American Journal of Agricultural Economics, vol. 92, issue 4, p. 1136-1148, 2010.

MILLER, R. E.; BLAIR, P. D. Input-output analysis: foundations and extensions. 2th ed. New York: Cambridge University Press, 2009.

MINISTÉRIO DA FAZENDA (2003). Disponível em: www.fazenda. gov.br

MINISTÉRIO DO DESENVOLVIMENTO, INDÚSTRIAE COMÉRCIO EXTERIOR (MIDIC) (Brasil). Sistema Aliceweb. Disponível em: $<$ http://aliceweb.desenvolvimento.gov.br $>$. Acesso em: 26 mar. 2009.

MONTALVÃO, E. Impacto de tributos, encargos e subsídios setoriais sobre as contas de luz dos consumidores. Centro de Estudos da Consultoria do Senado Federal, Texto para discussão n. 62, Brasília, set. 2009.

NARAYANAN, B.; WALMSLEY, T. L. (Eds.). Global trade, assistance, and production: The GTAP 7 data base, center for global trade analysis. West Lafayette: Purdue University, 2008. Disponível em: $<$ https://www.gtap.agecon.purdue.edu/databases/v7/default.asp $>$. Acesso em: 01 dez. 2009.

NUÑES, B. E. C; KURESKI, R. Contabilidade social para a economia do Paraná, 2000: tabelas básicas de insumo produção. In: ENCONTRO 
DE ECONOMIA PARANAENSE, 2., 2003, Maringá. Anais Maringá: UEM/UEL/UEPG/UNIOESTE/IPARDES, 2003, p. 241-259.

OECD - Organization for Economic Co-operation and Development. OECD Review of Agricultural Policies - Brazil, 2005.

PARRÉ, J.L. O agronegócio nas macrorregiões brasileiras: 1985 a 1995. Piracicaba: ESALQ, 2000. 191 p. Tese (Doutorado em Economia) - Escola Superior de Agricultura Luiz de Queiroz, Universidade de São Paulo.

PEREIRA, M.W.G.; TEIXEIRA, E.C. Construção da $\mathbf{1}^{\text {a }}$ base de dados do PAEG. PAEG Technical Paper N.2. Viçosa: DER/UFV.2009. 26 p.

PEREIRA, M.W.G.; TEIXEIRA, E.C. Construção da $2^{\text {a }}$ base de dados do PAEG. PAEG Technical Paper, n.3. Viçosa: DER/UFV, 8 p., 2009.

RUTHERFORD, T. F. Applied general equilibrium modeling with MPSGE as a GAMS subsystem: an overview of the modeling framework and syntax. Computational Economics, v. 14, n.1, p. 1-46, 1999.

RUTHERFORD, T. F., PALTSEV, S. V. GTAPinGAMS and GTAP$E G$ : global datasets for economic research and illustrative models. Working Paper. Boulder: Department of Economics, University of Colorado, 64 p., 2000.

RUTHERFORD, T. F. GTAP6inGAMS: The Dataset and Static Model. Prepared for the Workshop: "Applied General Equilibrium Modeling for Trade Policy Analysis in Russia and the CIS". Moscow: The World Bank Resident Mission, 42p., December 1-9, 2005.

SECRETARIA DO ORÇAMENTO FEDERAL (SOF) (Brasil). Estatísticas Fiscais. Disponível em: www.portalsof.planejamento.gov. br. Acesso em: 15 ago. 2010.

SIMON, E. J. A modernização da agricultura brasileira e o papel do crédito agrícola. 1992. 166 p. Tese (Doutorado em Economia) Universidade de São Paulo, São Paulo, SP. 


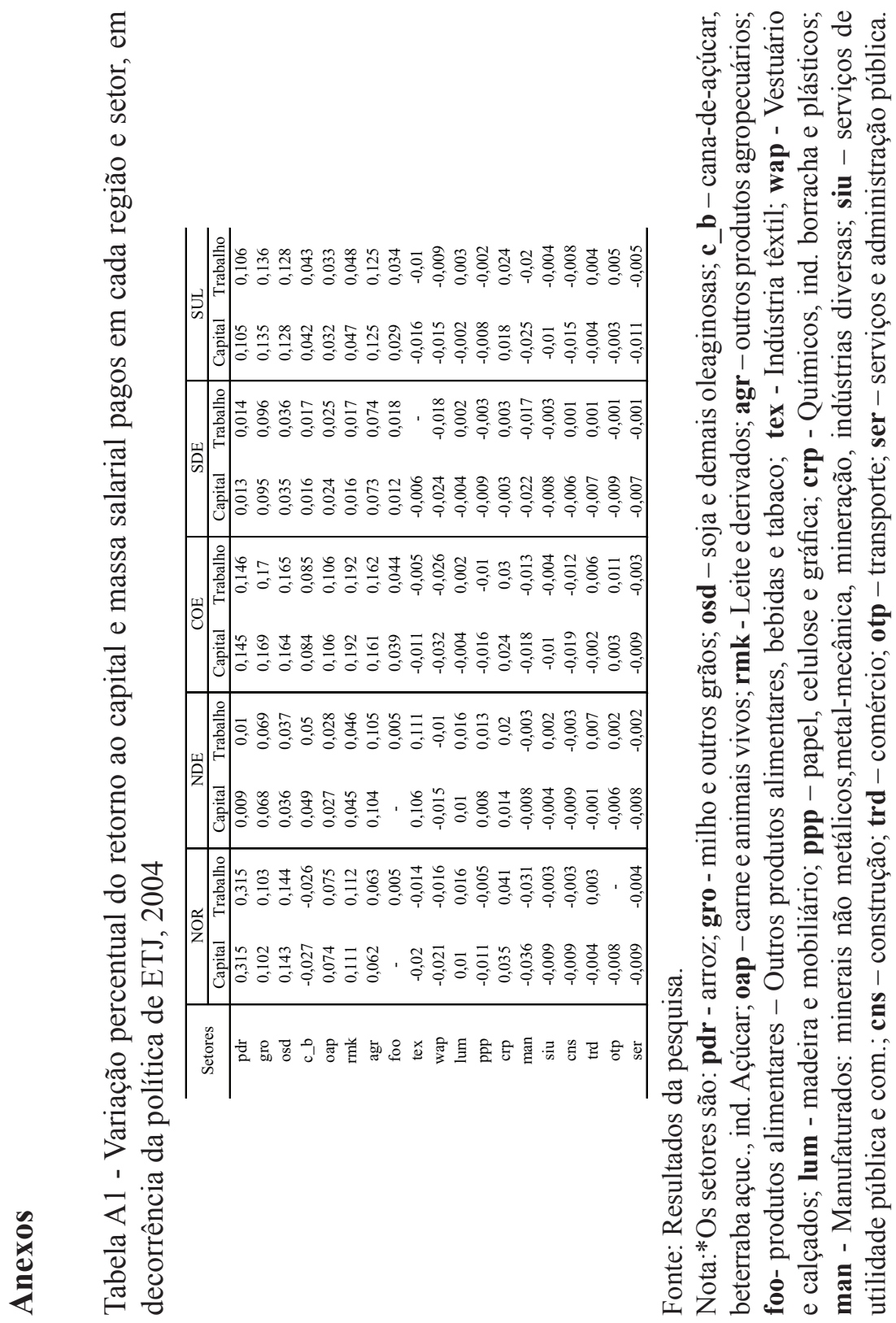

